\title{
Preparation of the Patient and Combined Topical Anaesthesia and Regional Nerve Blocks in Awake Nasal Intubation for Dental Surgeries
}

\author{
Vatsal C. Patel ${ }^{1}$, Rinku T. Patel ${ }^{2}$, Aakanksha Raval ${ }^{3}$, Nishant B. Patel ${ }^{4}$, Rutu R. Patel ${ }^{5}$
}

\begin{abstract}
${ }^{1}$ Assistant Professor, Department of Anaesthesiology, Smt. NHL Municipal Medical College, Ahmedabad, Gujarat, India. ${ }^{2}$ Assistant Professor, Department of Anaesthesiology, Smt. NHL Municipal Medical College, Ahmedabad, Gujarat, India. ${ }^{3} 3^{\text {rd }}$ Year Resident, Department of Anaesthesiology, Smt. NHL Municipal Medical College, Ahmedabad, Gujarat, India. ${ }^{4} 3^{\text {rd }}$ Year Resident, Department of Anaesthesiology, Smt. NHL Municipal Medical College, Ahmedabad, Gujarat, India. ${ }^{5} 2^{\text {nd }}$ Year Resident, Department of Anaesthesiology, Smt. NHL Municipal Medical College, Ahmedabad, Gujarat, India.
\end{abstract}

\section{ABSTRACT}

\section{BACKGROUND}

The largest class of causes leading to mortality and serious morbidity in anaesthesia are from airway complications. Failure to intubate and ventilate are responsible for about one third of all anaesthetic deaths. Newer techniques like awake blind nasal intubation, fiberoptic intubation and video laryngoscopy have been introduced to tackle conditions like trismus, oral injuries, oral tumours, inadequate mouth opening, predicted difficult airway, restricted neck movement and anatomical deformities. We wanted to assess the efficiency and adequacy of combined topical anaesthesia and regional nerve blocks in awake nasal intubation for dental surgeries.

\section{METHODS}

After approval of the study by the ethical committee of the hospital, a prospective observational study was done on 35 adult patients with ASA grade I-II. A written informed consent was obtained from each patient. A preoperative evaluation including a complete airway assessment was done. According to standard guidelines premedication was given. The efficiency and adequacy of combined topical anaesthesia and nerve blocks in awake nasal intubation is assessed for dental surgeries using Intubation Score, Patient's Comfort Score, Intubation Time, Intubation Attempt and Patient's Satisfaction Score.

\section{RESULTS}

In our study, we observed an increase in HR, SBP, DBP and mean arterial pressure during intubation (maximum seen at the time of tracheal intubation), whichlateron settled until the $3^{\text {rd }}$ and $4^{\text {th }}$ min after intubation was done. In our study, the efficiency and adequacy of blocks given were assessed by using intubation scores which included (a) cough score (b) limb movements which showed successful application of block in around $80 \%$ of patients. The further comfort of the patient was assessed by using 5-point patient comfort score during the procedure and 3-point comfort score after awake intubation. Patient satisfaction score was assessed postoperatively, and majority of patients showed excellent satisfactionscore.

\section{CONCLUSIONS}

Awake nasotracheal intubation done under topical anaesthesia and combined regional nerve blocks is associated with good intubating conditions and patient comfort with minimal effect on hemodynamics.

\section{KEY WORDS}

Awake Nasal Intubation, Topical Anaesthesia, Superior Laryngeal block, Transtracheal Block, Bupivacaine, Xylometazoline

\author{
Corresponding Author: \\ Dr. Vatsal C. Patel, \\ A 101, Arjun Grace-Apartment, \\ Opp. Swaminarayan Temple, \\ Near Naranpura Tele Exchange, \\ Shashtrinagar, Ahmedabad-380063, \\ Gujarat, India. \\ E-mail: pvatsal14@gmail.com
}

DOI: $10.14260 /$ jemds/2019/594

Financial or Other Competing Interests: None.

How to Cite This Article:

Patel VC, Patel RT, Raval A, et al. Preparation of the patient and combined topical anaesthesia and regional nerve blocks in awake nasal intubation for dental surgeries. J. Evolution Med. Dent. Sci. 2019;8(35):2738-2742, $10.14260 /$ jemds/2019/594

Submission 12-07-2019,

Peer Review 20-08-2019,

Acceptance 26-08-2019,

Published 02-09-2019. 


\section{BACKGROUND}

The largest class of causes leading to mortality and serious morbidity in anaesthesia are from airway complications. Failure to intubate and ventilate are responsible for about one third of all anaesthetic deaths. Newer techniques like awake blind nasal intubation, fiberoptic intubation and video laryngoscopy have been introduced to tackle such situations. Such conditions include trismus, oral injuries, oral tumours, inadequate mouth opening, predicted difficult airway, restricted neck movement and anatomical deformities. The American Society of Anaesthesiologists Task Force describes difficult airway as the clinical situation in which an anaesthetist experiences difficulty with facemask ventilation, difficulty in supraglottic device ventilation, difficulty in tracheal intubation or all three. ${ }^{1}$ Canadian airway focus group defines difficult intubation as when an experienced anaesthetist, using direct laryngoscopy, requires more than two attempts with the same blade/ change in the blade or an adjunct to direct laryngoscope (i.e., bougie) or use of an alternative device or technique following failed intubation with direct laryngoscopy. Difficult laryngoscopy equates to Cormack and Lehane's grade 3 or 4 view of the larynx. The airway can be rapidly assessed (even in an emergency situation) by a simple 1-2-3 rule. The ability to insinuate the tip of 1 finger into the temporomandibular joint (TMJ) space in front of the tragus is assessed during opening and closing of the mouth. It indicates adequate mobility of the TMJ. An inter-incisor gap of at least 2 fingerbreadths between the upper and lower incisors indicates adequate space between the jaws for introduction of a laryngoscope blade, thereby facilitating exposure of glottis and ensuring sufficient room for the passage of an endotracheal tube. A thyromental distance (TMD) of more than 3 fingerbreadths measured between the thyroid notch and the symphysis menti is used to evaluate the space available for displacement of the tongue during laryngoscopy and intubation. Other aspects of airway examination that could predict a possible difficulty in endotracheal intubation include modified Mallampati class, head and neck movements, subluxation of the mandible, a receding mandible and neck circumference.[1]

Ask and look for a previous history of difficult mask ventilation or intubation. Reduced neck mobility in case of rheumatoid arthritis, ankylosing spondylitis, osteoarthritis, surgical fixation of cervical spine; reduced mouth opening due to reduced TM joint mobility, trismus scarring and fibrosis, local lesions, swelling; lesions of the larynx, pharynx and tongue like tumours, fibrosis, swelling; congenital deformities and conditions with facial deformities (Goldenhar, Pierre Robin), achondroplasia all should arouse a suspicion of a suspected difficult airway.

\section{METHODS}

After approval of the protocol by the ethical committee of the hospital, a prospective observational study was done on 35 adult patients with ASA grade I - II over period of one month (30 days).A written informed consent was obtained from each patient. The patients were aged 20-50 years. Uncooperative patients, patients with known allergy to local anaesthetics, patients with a history of epilepsy, asthmatics, patients with deranged coagulation profile, hemodynamic instability, or with an infection at local site were excluded from the study. Preoperative evaluation including a complete airway assessment was done. Standard fasting guidelines along with anti-aspiration prophylaxis with tablet ranitidine $150 \mathrm{mg}$ were prescribed.

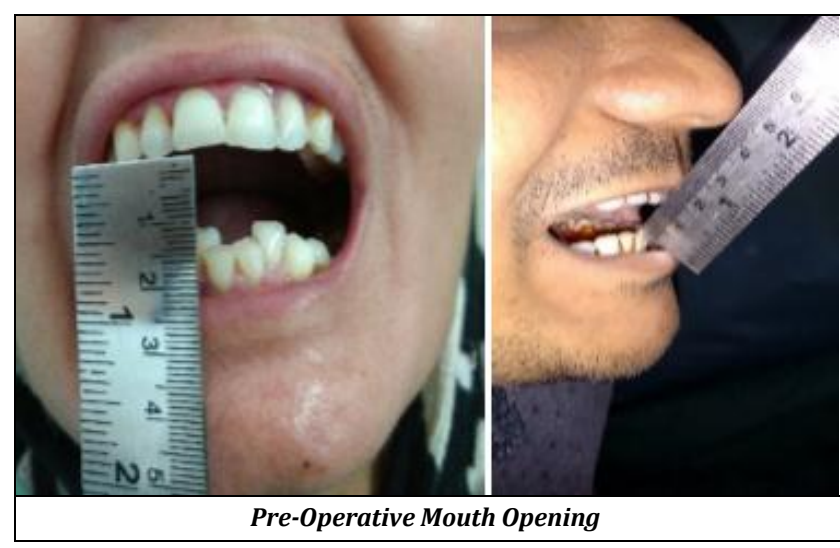

\section{In Operation Theatre}

The patients were explained about the procedure briefly. Winning the patient's confidence and cooperation is particularly important when endotracheal intubation is planned in the awake state. The anaesthesiologist must describe to the patient in a careful and unhurried manner (Using as few medical terms as possible), the reason why securing the airway in the awake state is of utmost importance despite the conventional technique following induction of anaesthesia being more comfortable for the patient It must be made amply clear that endotracheal intubation in the awake state under topical anaesthesia is ideal because of its inherent safety. The patients were informed that they would experience some degree of discomfort while the airway was being secured in the awake state. A realistic description of the degree of discomfort and unpleasantness to be anticipated during awake intubation will go a long way in obtaining the trust and cooperation of the patient. A written informed consent detailing the entire procedure of endotracheal intubation in the awake state completed the preoperative psychological preparation of the patient. Monitoring including electrocardiography, noninvasive blood pressure, pulse oximetry and end tidal $\mathrm{CO} 2$ were applied in all patients. An intravenous line was secured, and Ringers lactate was started at $10-15 \mathrm{ml} / \mathrm{Kg}$. After recording baseline heart rate, blood pressure and oxygen saturation, injection glycopyrrolate $5-10 \mathrm{mcg} / \mathrm{kg} \mathrm{I.M.} \mathrm{(before}$ 30 mins), inj. midazolam 0.05-0.15 mg/kg I.V. and inj. fentanyl 1-2 mcg/kg I.V. was given as premedication.

\section{Patient Preparation}

For the purpose of anaesthetizing the upper airway, it can be thought of as having four parts- nasal cavity and nasopharynx, oral cavity and oropharynx, larynx above the vocal cords and larynx below the vocal cords.

\section{Topical Anaesthesia}

For anaesthetizing the nasal cavity, nasopharynx, oral cavity and oropharynx, a mixture of plain lignocaine $(2 \%) 5 \mathrm{ml}$, lignocaine + adrenaline (2\%) $5 \mathrm{ml}$ and xylometazoline 8-10 drops was prepared. 2 nasal wicks soaked in it were placed, 
one in each nostril of the patients. Nebulisation with 3-4 ml of the prepared mixture 30 minutes before induction was done. The patients were asked to gargle with the remaining mixture. Lignocaine used during topical application of local anaesthetic to the upper airway results in plasma concentrations well below those that cause symptoms of toxicity (toxic level $6 \mathrm{mcg} / \mathrm{ml}$ ). Symptoms of lignocaine toxicity include circumoral numbness, facial tingling, restlessness, vertigo, tinnitus, slurred speech among others and severe toxicity may also lead to convulsions, respiratory failure and circulatory collapse. Lipid emulsion therapy should be started at the earliest sign of lignocaine toxicity. $20 \%$ intralipid administered in a bolus dose of $1.5 \mathrm{ml} / \mathrm{kg}$ lean body mass followed by infusion of $20 \%$ intralipid at 15 $\mathrm{ml} / \mathrm{kg} / \mathrm{hr}$ upto a maximum dose of not more than $12 \mathrm{ml} / \mathrm{kg}$ should be administered.

\section{Nerve Blocks}

Superior laryngeal nerve block for larynx above the vocal cords, and transtracheal block for the recurrent laryngeal nerve supplying larynx and trachea below the cords were used to anaesthetize the airway for awake intubation.

\section{Superior Laryngeal Nerve Block}

The superior laryngeal nerve provides sensation to the laryngeal structures above the vocal cords and lies inferior to the cornu of the hyoid bone. Here, it splits into the internal and external branches. The internal branch then penetrates the thyrohyoid membrane about 2-4 $\mathrm{mm}$ inferior to the greater cornu, continuing submucosally in the piriform recess. The external branch does not penetrate the thyrohyoid membrane; it descends on the larynx deep to the sternothyroid muscle. The superior laryngeal nerve can be blocked using the external or internal approach. The patient's head was extended as much as possible in supine position with the help of a head ring and a sandbag. The patient's skin was cleaned with an appropriate antimicrobial solution (Betadine). The cornu of the hyoid bone was located below the angle of the mandible. One hand was used to displace the hyoid bone contralaterally, bringing ipsilateral cornu and internal branch of superior laryngeal nerve closer. A 1.5", 23-gauge needle was inserted in an anteroinferior medial direction until the lateral aspect of the greater cornu was touched. The needle was walked downward toward the midline (1-2 $\mathrm{mm}$ ) off the inferior border of the greater cornu, the thyrohyoid membrane was pierced The syringe was then aspirated and after confirming negative aspiration for air and blood, $2 \mathrm{ml}$ of LA ( $2 \%$ lidocaine) was injected to block the internal branch of superior laryngeal nerve. Same procedure was repeated on opposite side.

\section{Transtracheal Block}

The sensory innervation of the vocal cords and trachea is supplied by the recurrent laryngeal nerves. These ascend along the tracheoesophageal groove and also provide the motor supply to all the intrinsic muscles of the larynx except the cricothyroid muscle. Direct recurrent laryngeal nerve blocks are not performed as they can result in bilateral vocal cord paralysis and airway obstruction, as both the motor and the sensory fibres run together. Technique for blocking the sensory input of the recurrent laryngeal nerve is by transtracheal block. In this technique, the cricothyroid membrane was located in the midline of the neck. It was located by the three-finger palpating the thyroid prominence and proceeding in a caudal direction. The cricothyroid membrane was identified as the spongy fibromuscular band between the thyroid and cricoid cartilages. After sterile skin preparation, the overlying skin was anesthetized by raising a small skin wheal of LA. Then a 22-gauge needle on a syringe with $4 \mathrm{ml}$ of $2 \%$ lidocaine was passed perpendicular to the axis of the trachea piercing the membrane. While the needle was advanced, the syringe was continuously aspirated. The needle was advanced until air was freely aspirated, signifying that the needle was in the trachea. Instillation of LA at this point invariably lead to coughing. Through coughing, the LA was dispersed diffusely blocking the sensory nerve endings of the recurrent laryngeal nerve. Now the patients had received topical anaesthesia and two regional blocks.

\section{Intubation}

$2 \%$ xylocaine jelly was put through the appropriate nostril after selecting the more patent nostril by occlusion test or the spatula test and patients were asked to inhale deeply till it reached pharynx. Portex cuffed nasal RAE of appropriate size was passed through it. Patients were asked to take deep breaths and breath sound was followed for advancement of endotracheal intubation. With slight flexion of the neck, the endotracheal tube was pushed which slipped through the vocal cords during deep inspiration. The position of endotracheal tube was confirmed using EtCO2 monitor, breath sounds and movement on reservoir bag. Anaesthesia was induced with inj. Propofol 1-2 mg/kg iv followed by inj. Atracurium $0.4-0.5 \mathrm{mg} / \mathrm{kg}$ iv. The cuff of the endotracheal tube was inflated till the audible leak disappeared. Anaesthesia was maintained on nitrous oxide, oxygen and sevoflurane. Muscle relaxation and respiration was controlled with inj. atracurium $0.08-0.1 \mathrm{mg} / \mathrm{kg}$ iv. Intraoperative period was uneventful. Inj. Dexona $8 \mathrm{mg}$ iv was given to reduce airway oedema. Patients in whom we failed to intubate were excluded from the study. Vital parameters (HR, BP, SPO2) were recorded at baseline and thereafter an interval of $1 \mathrm{~min}$ until intubation was done followed by every 2 minutes until $10 \mathrm{~min}$ after intubation and thereafter all throughout till extubation. Other parameters recorded were intubation score, patients' comfort score, intubation time, intubation attempt and patients' satisfaction score postoperatively.

\section{Intubation Score}

Assessed during the passage of RAE tube to assess the efficacy of airway blocks.

\section{Coughing \\ None/Slight/Moderate/Severe.}

\section{Limb Movement}

None/Slight/Moderate/Severe.

\section{Patient's Comfort Score}

Intraoperatively was assessed using the following scores

\section{5-Point Intubation Comfort Score}

No reaction/Slight grimacing/Heavy grimacing/Verbal objection/Defensive movement of hands or head. 


\section{3-Point Score Immediately after Intubation}

Cooperative/Restless-minimal resistance/Severe resistance.

After surgery, neuromuscular blockade was reversed with inj. glycopyrrolate $0.4 \mathrm{mg}$ iv and inj. Neostigmine 0.05 $\mathrm{mg} / \mathrm{kg}$ iv. Extubation was uneventful. Vital parameters were monitored throughout procedure and found to be stable. Patients were shifted to recovery room with oxygen mask.

\section{Patient Satisfaction Score Postoperatively \\ Excellent/Good/Reasonable/Poor}

\section{Statistical Significance}

In this study paired sample t-test can be applied for statistical significance. The paired sample $\mathrm{T}$ test also called dependent sample $\mathrm{T}$ test is statistical procedure used to determine the mean difference between two sets of observation. In paired $\mathrm{T}$ test each subject or entity is measured twice, resulting in pair of observation. Heart rate and Mean arterial pressure at baseline and 10 minutes after intubation are observed and paired T value calculated. Paired $\mathrm{T}$ value for difference in heart rate-2.75. $\mathrm{p}$ Value 0.004739 $(<0.05)$. Paired $t$ value for difference in Mean arterial pressure -3.12. p Value $0.001837(<0.05)$. The $p$ value supports null hypothesis.

\section{RESULTS}

\begin{tabular}{|c|c|}
\hline Age (Years) & $38.2 \pm 10.74$ \\
\hline Weight (Kg) & $64.13 \pm 7.12$ \\
\hline Gender & $\mathrm{M}: \mathrm{F} 20: 15$ \\
\hline Duration of Surgery (Mins) & $84 \pm 74.98$ \\
\hline Table 1. Demographic Data \\
\hline
\end{tabular}

The dental surgeries for which awake nasal intubation was fibrotomy in oral submucous fibrosis, ankylosis release in temporomandibular joint, mandibular plating, space infection patients who require incision and drainage, oral and maxillofacial tumours etc.

\section{Vital Parameters}

There was a gradual increase in HR, systolic BP (SBP) and diastolic BP (DBP) at each minute during intubation. Maximum changes were seen at the time of intubation from the basal value, which was significant and gradually normalized towards the basal levels after $3^{\text {rd }}-4^{\text {th }}$ min of intubation and even lesser until $10^{\text {th }}$ min of monitoring. Up to $20 \%$ deviation from the baseline vitals, no pharmacological intervention was done. The SpO2 was well maintained throughout the procedure with insignificant falls seen during intubation.

\begin{tabular}{|c|c|c|c|c|}
\hline & HR & SBP & DBP & MAP \\
\hline Basal Value & $79.32 \pm 8.86$ & $125.4 \pm 9.11$ & $70.96 \pm 5.58$ & $86.2 \pm 3.9$ \\
\hline At intubation & $92.12 \pm 9.11$ & $142 \pm 8.95$ & $84.36 \pm 5.35$ & $103.6 \pm 6.2$ \\
\hline $2^{\text {nd }} m i n$ after intubation & $86.03 \pm 8.10$ & $136 \pm 7.45$ & $80.32 \pm 6.78$ & $99.2 \pm 3.7$ \\
\hline $4^{\text {th }} m i n$ after intubation & $79.52 \pm 8.14$ & $128.4 \pm 8.86$ & $72.98 \pm 5.36$ & $91.4 \pm 5.4$ \\
\hline $6^{\text {th }}$ min after intubation & $77.98 \pm 7.12$ & $120.6 \pm 5.46$ & $70.7 \pm 7.45$ & $87.4 \pm 7.3$ \\
\hline $8^{\text {th }} m$ in after intubation & $75.84 \pm 3.36$ & $119.6 \pm 3.4$ & $68.45 \pm 44$ & $85.6 \pm 3.8$ \\
\hline $10^{\text {th }}$ min after intubation & $73.32 \pm 6.70$ & $116.04 \pm 7.45$ & $66.72 \pm 4.51$ & $83.5 \pm 1.4$ \\
\hline \multicolumn{5}{r}{ Table 2. Hemodynamic Changes } \\
\hline
\end{tabular}

\section{Intubation Score}

2 patients had no coughing episodes, whereas only one patient out of all had severe coughing due to retained sensitivity of laryngeal surface despite the blocks. 18 patients did not move their limbs while the procedure was being carried out. 14 patients moved their arms and legs slightly to moderately. In 2 patients the block was not effective.

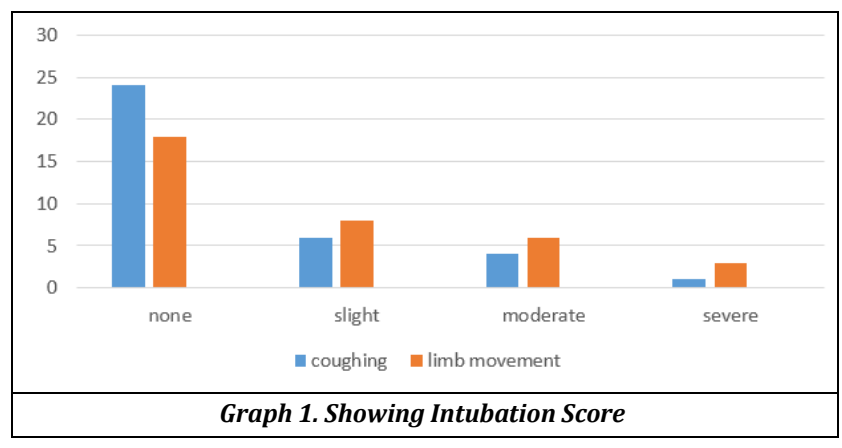

\section{Patient Comfort Score}

Further comfort of the patient was assessed using 5-point patient comfort score during the procedure, 3- point comfort score after awake orotracheal intubation and patient satisfaction score was seen postoperatively also.
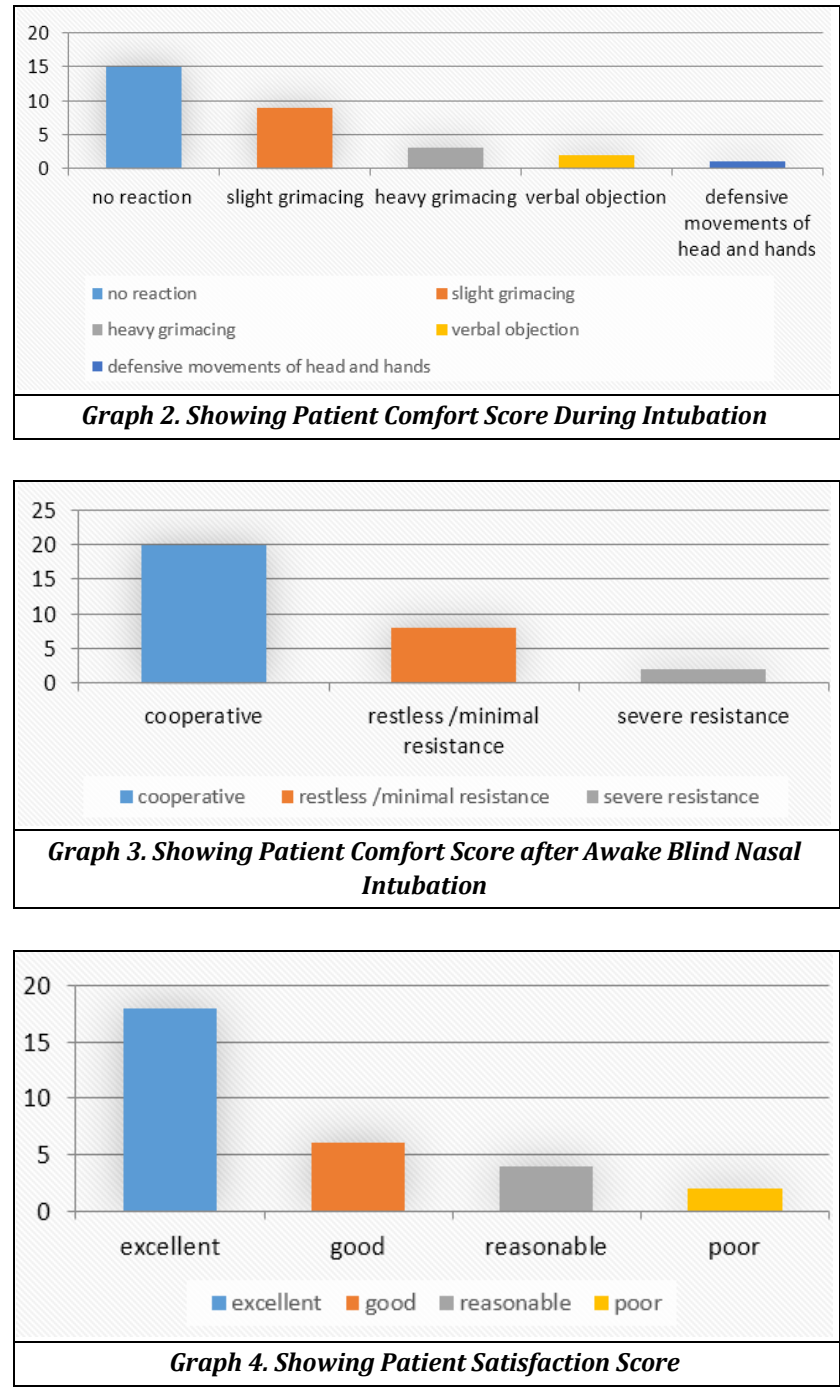
DISCUSSION

Fibreoptic intubation is the gold standard for managing difficult airway. The use of awake blind nasotracheal intubation is well-established and has been extensively supported in the literature for managing the difficult airway. These include, but are not limited, to the following: Compromised airway, restricted or limited neck movement, anatomic deformities, and in general anesthesia where intubation may become highly difficult and challenging in the face of the difficult airway. The difficult airway algorithm which includes a call for help in such a scenario may not be applicable in this case as we do not have much time left after paralyzing the patient.[2] An awake nasal intubation allows the patient to maintain the tonicity of the airway muscles providing a degree of safety that may be lost in the anesthetized, paralyzed patient.[3] Patients' cooperation is very important. Keys to successful intubation include control of secretions by the use of an antisialagogue, adequate sedation to alleviate anxiety, and adequate anesthesia to ensure patient comfort. Through this technique, we blocked the three major reflexes of the patients including gag reflex, cough reflex, and glottis closure reflex by blocking bilateral superior laryngeal, and recurrent laryngeal nerves. In our study, we observed an increase in HR, SBP, DBP and mean arterial pressure during the procedure of intubation (Maximum seen at the time of tracheal intubation) which later on settled until the $3^{\text {rd }}$ to $4^{\text {th }}$ min after intubation was done, which was similar to that observed by Ovassapian et al[ ${ }^{[4]}$ while performing nasotracheal intubation in awake patients under LA. In a study conducted by Trivedi and Patil[5] in 2009 in which they evaluated airway blocks versus general anesthesia, they concluded that hemodynamic changes were less in airway block patients.

Kundra et al.[6] in 2000 conducted a study which compared two methods of anesthetizing the airway for awake fiberoptic nasotracheal intubation which included nebulization with $4 \mathrm{ml}$ of $4 \%$ lidocaine and the other received airway block (Trans laryngeal, bilateral superior laryngeal, and lidocaine-soaked cotton swabs in the nose). It was seen that patients who received lidocaine nebulization for airway anesthesia had to undergo significantly higher stress during the insertion of an endotracheal tube through the glottis. The grimace scores, as well as the mean HR and $\mathrm{BP}$ in the nebulization group, were significantly higher during endotracheal tube insertion. Gupta et al.[7] conducted a study in 2014 which also showed that patient comfort was better in the nerve blocks group as compared with the nebulization group and also vocal cord visibility and ease of intubation as assessed by the bronchoscopist were better in the nerve block group as compared with the nebulization group. Trivedi and Patil[5] also showed that postoperative analgesia was better, patients were more calm and required less postoperative nebulization who were given airway block as compared to general anesthesia for taking a laryngeal biopsy.
In our study, the efficiency and adequacy of the blocks given were assessed by using Intubation scores which included (a) Cough score (b) Limb movements which showed successful application of block in around $80 \%$ of patients. The further comfort of the patient was assessed by using 5 point patient comfort score during the procedure and 3-point comfort score after awake orotracheal intubation. Patient satisfaction score was assessed postoperatively, and majority of patients showed excellent satisfaction score.

\section{CONCLUSIONS}

Awake nasotracheal intubation done under topical anaesthesia and combined regional nerve blocks is associated with good intubating conditions and patient comfort with minimal effect on hemodynamics.

\section{ACKNOWLEDGEMENT}

This research was supported by AMC dental college and hospital, Ahmedabad. We are thankful to our colleagues who provided expertise that greatly assisted the research. We have to express our appreciation to our respected faculty members who shared their pearls of wisdom with us during the course of this research.

\section{REFERENCES}

[1] www.canadianairwayfoccusgroup.org

[2] Ramkumr V. Preparation of the patient and airway for awake intubation. Indian J Anesthesia 2011;55(5):442-7.

[3] Lallo A, Billard V, Bourgain JL. A comparison of propofol and remifentanil target-controlled infusions to facilitate fiberoptic nasotracheal intubation. Anesth Analg 2009;108(3):852-7.

[4] Ovassapian A, Yelich SJ, Dykes MH, et al. Blood pressure and heart rate changes during awake fiberoptic nasotracheal intubation. Anesth Analg 1983;62(10):9514.

[5] Trivedi V, Patil B. Evaluation of airway blocks versus general anesthesia for diagnostic direct laryngoscopy and biopsy for carcinoma of the larynx. A study of 100 patients. Internet J Anesthesiol 2009;26:1.

[6] Kundra P, Kutralam S, Ravishankar M. Local anaesthesia for awake fiberoptic nasotracheal intubation. Acta Anaesthesiol Scand 2000;44(5):511-6.

[7] Gupta B, Kohli S, Farooque K, et al. Topical airway anaesthesia for awake fiberoptic intubation: comparison between airway nerve blocks and nebulized lignocaine by ultrasonic nebulizer. Saudi J Anaesth 2014;8(Suppl 1):S15-9. 